\title{
INFLUÊNCIA DO MANEJO DA IRRIGAÇÃO NO MELOEIRO RENDILHADO CULTIVADO EM AMBIENTE PROTEGIDO
}

\author{
TONNY J. A. SILVA ${ }^{1}$, CARMELLO C. MACHADO ${ }^{2}$, EDNA M. BONFIM-SILVA ${ }^{3}$, \\ RUBENS D. COELHO ${ }^{4}$
}

\begin{abstract}
RESUMO: Visando a avaliar a cultura do melão rendilhado em função do manejo da irrigação, foi realizado um experimento em casa de vegetação com a cultivar Bônus $\mathrm{n}^{\mathrm{o}}$ 2, na área experimental do Departamento de Engenharia Rural da Escola Superior de Agricultura "Luiz de Queiroz" ESALQ/USP. Foram avaliados dois sistemas de manejo (tensiômetro e lisímetro de tensão controlada), e dois níveis de fertilidade (presença e ausência de fertilizantes). O lisímetro de tensão controlada é um dispositivo que utiliza cápsula porosa, capaz de fornecer água automaticamente, acoplado a um tubo de Mariotte, que permite realizar leituras de volume de água consumido pela planta. Para os tratamentos com lisímetro de tensão controlada, a porosidade livre de água média ( $P L A)$ foi de 15\%; já para os irrigados com base nos tensiômetros, a PLA permaneceu em média $35 \%$, favorecendo boa relação arágua durante todo o experimento. Com relação à variação temporal do potencial matricial do solo (média das três profundidades), os tratamentos com tensiômetro apresentaram valores médios de tensões com desvios de $9,10 \%$, enquanto, para os tratamentos com lisímetro de tensão controlada, os desvios foram de $1,33 \%$. Com manejo da irrigação por tensiômetros, sem adição de fertilizantes, a massa média dos frutos $(1.070,4 \mathrm{~g})$ quase duplicou em relação ao padrão mínimo comercial $(550 \mathrm{~g})$. Adicionando a fertirrigação nesse manejo, o incremento passou a ser de 4,5 vezes $(2.493,8 \mathrm{~g})$. O meloeiro apresentou baixo rendimento em condição de porosidade livre de água inferior a $20 \%$.
\end{abstract}

PALAVRAS-CHAVE: lisímetro, cápsula porosa, Mariotte.

\section{IRRIGATION MANAGEMENT ON NET-MELON FRUITS CULTIVATED UNDER GREENHOUSE}

\begin{abstract}
Aiming to evaluate net-melon fruits under irrigation management, it was carried out an experiment in greenhouse conditions. The experimental area was located at the irrigation farm of the Engineering Department of - Escola Superior de Agricultura "Luiz de Queiroz" - ESALQ/USP in Piracicaba, São Paulo, Brazil, planted with Bonus 2 cultivar. Two irrigation management systems were evaluated by tensiometer and tension lysimeter with two levels of solution fertility (presence and absence). Tension lysimeter is a device based on porous cap, capable of supplying water automatically to the plant through a Mariotte reservoir (constant hydraulic head). For the treatments with tension lysimeter, the average free water porosity $(P L A)$ was $15 \%$. For treatments with tensiometers, the PLA was $35 \%$ in average, favoring a good relation of air-water throughout the experiment. The temporal variation of the matrix potential in treatments by tensiometer, measured in three depths, presented an average deviation of $9.10 \%$ whereas treatments with tension lysimeter were $1.33 \%$. The irrigation management by tensiometers without fertilizer obtained an average weight of the fruits $(1,070.4 \mathrm{~g})$ that was almost duplicated in relation to minimum commercial standard $(550 \mathrm{~g})$. However, by adding fertilizer in these plants the productivity increment was 4.5 times higher $(2,493.8 \mathrm{~g})$. The net-melon fruits presented a low productivity when the free water porosity was lower at $20 \%$.
\end{abstract}

KEYWORDS: lysimeter, porous cup, Mariotte

\footnotetext{
${ }^{1}$ Eng o Agrônomo, Doutorando em Irrigação e Drenagem, Escola Superior de Agricultura "Luiz de Queiroz”, ESALQ/USP, Piracicaba SP, Fone: (0XX19) 34294217 - R:266, tonny@iac.sp.gov.br

${ }^{2}$ Doutorando em Irrigação e Drenagem, ESALQ/USP, Piracicaba - SP.

${ }^{3}$ Zootecnista, Doutora em Solos e Nutrição de Plantas, ESALQ/USP, Piracicaba - SP.

${ }^{4}$ Prof. Doutor, Departamento de Engenharia Rural, ESALQ/USP, Piracicaba - SP.

Recebido pelo Conselho Editorial em: 5-2-2004

Aprovado pelo Conselho Editorial em: 19-10-2005
} 


\section{INTRODUÇÃO}

O cultivo do melão rendilhado (Cucumis melo var. reticulatus, Naud.) apresenta boa cotação comercial e pode ser realizado em pequenas áreas com boa lucratividade. O local de cultivo deve ter boa luminosidade, temperatura elevada, baixa umidade, além de boas condições de irrigação. Esses fatores favorecem a redução do ciclo vegetativo (RIZZO, 1999).

Por se tratar de uma cultura que permite mais de uma colheita por ano, atingindo altos níveis de produtividade (1.800-3.000 frutos por $1.000 \mathrm{~m}^{2}$ de estufa por ano) (BRANDÃO FILHO \& VASCONCELLOS, 1998), um bom manejo de irrigação deve ser realizado.

O manejo da irrigação permite a manutenção da umidade do solo em níveis adequados à cultura, porém o meloeiro não tolera excesso de umidade, e essa situação favorece o surgimento de doenças fúngicas, principalmente podridões do cólon [Didymella bryoniae (Aversw) Rehm] (GUALBERTO et al., 2001). RIZZO \& BRAZ (2001), avaliando características de algumas variedades de melão rendilhado em Jaboticabal - SP, obtiveram produções menores que a média regional, devido à ocorrência de podridões do cólon causada por excesso de umidade.

Dentre diferentes métodos de controle de irrigação, os tensiômetros de cápsula de cerâmica porosa são os mais utilizados. A cerâmica porosa possui uma gama de aplicações nas mais diversas áreas, desde matéria-prima na fabricação de componentes eletrônicos, restituição de partes de ossos (próteses), sistemas de filtragens diversos, parte de sensores em automação, etc. Na área agrícola, esse material tem importante aplicação nos equipamentos de monitoramento da água no solo (tensiômetros e extratores de solução). Outras aplicações vêm sendo pesquisadas, como, por exemplo, a utilização de cápsulas porosas em sistemas de irrigação subsuperficial para experimentos científicos (BATAGLIA, 1989; SILVA et al., 2004) ou em lisímetros de tensão controlada (ABOUKHALED et al., 1986).

Neste trabalho, teve-se o objetivo de avaliar o manejo da irrigação no cultivo do melão rendilhado em ambiente protegido, por meio de lisímetro de tensão controlada e com base em leituras tensiométricas sob duas condições de fertilidade do solo.

\section{MATERIAL E MÉTODOS}

O experimento foi conduzido em estufa trigeminada do tipo túnel alto ( $3,0 \mathrm{~m}$ de pé-direito), localizada nas coordenadas $22^{\circ} 43^{\prime} 33^{\prime}$ ' de latitude sul, $47^{\circ} 38^{\prime} 0^{\prime \prime}$ ' de longitude oeste e altitude de $576 \mathrm{~m}$, na área experimental de Irrigação e Drenagem do Departamento de Engenharia Rural, da Escola Superior de Agricultura "Luiz de Queiroz" - ESALQ/USP, durante os meses de setembro de 2002 a janeiro de 2003. Nesse período, as temperaturas médias mensais foram: 20,3; 25,9; 25,1; 25,3 e $24,7^{\circ} \mathrm{C}$.

A semeadura foi realizada em 12-9-2002, em bandejas de poliestireno, com 128 células contendo substrato comercial. A germinação ocorreu sete dias após a semeadura, e o transplantio, aos 20 dias após a germinação. Realizou-se o transplantio de duas mudas por vaso, sendo uma das mudas desbastada sete dias após o transplantio, permanecendo uma planta por vaso. Para isso, utilizaram-se 18 recipientes plásticos (vasos) com volume total de 59,6 L, preenchidos com solo até $5 \mathrm{~cm}$ abaixo da borda, justapostos em fileira única distante $1,5 \mathrm{~m}$ da lateral da casa de vegetação, e espaçadas de $0,43 \mathrm{~m}$ entre plantas.

As mudas de melão da cultivar Bônus $\mathrm{n}^{\mathrm{o}} 2$ foram transplantadas para os vasos, em uma pequena cova $(0,1 \times 0,1 \times 0,1 \mathrm{~m})$. O solo utilizado foi um Latossolo Vermelho-Amarelo (EMBRAPA, 1999) com textura franco arenosa, coletado numa profundidade de $0-0,3 \mathrm{~m}$, com as características físicas: $185 \mathrm{~g} \mathrm{~kg}^{-1}$ de argila, $120 \mathrm{~g} \mathrm{~kg}^{-1}$ de silte e $695 \mathrm{~g} \mathrm{~kg}^{-1}$ de areia. A densidade de partículas foi de $2,66 \mathrm{Mg} \mathrm{m}^{-3}$ e a densidade do solo igual a $1,1 \mathrm{Mg} \mathrm{m}^{-3}$. Algumas propriedades químicas do solo são 
apresentadas na Tabela 1. Seguindo a recomendação do Boletim 100 (IAC), foi realizada fertilização de fundação com $5 \mathrm{~L}$ de esterco bovino por vaso.

Para avaliar as relações de produção, utilizou-se do delineamento experimental em blocos ao acaso, com arranjo fatorial 2 × 2 (dois sistemas de reposição de água, dois níveis de fertirrigação), em três repetições, com uma planta por parcela experimental.

TABELA 1. Propriedades químicas determinadas do Latossolo Vermelho-Amarelo.

\begin{tabular}{|c|c|c|c|c|c|c|c|c|c|}
\hline \multirow{2}{*}{$\begin{array}{c}\mathrm{pH} \\
\mathrm{CaCl}_{2}\end{array}$} & $\mathrm{MO}$ & $\mathrm{P}$ & $\mathrm{K}$ & $\mathrm{Ca}$ & $\mathrm{Mg}$ & $\mathrm{H}+\mathrm{Al}$ & SB & $\mathrm{T}$ & \multirow{2}{*}{$\begin{array}{c}\mathrm{V} \\
(\%)\end{array}$} \\
\hline & $\mathrm{g} \mathrm{dm}^{-3}$ & $\mathrm{mg} \mathrm{dm}^{-3}$ & \multicolumn{6}{|c|}{$\mathrm{mmol}_{\mathrm{c}} \mathrm{dm}^{-3}$} & \\
\hline 4,6 & 21,0 & $5,0_{\mathrm{MB}}$ & $1,8_{\mathrm{ME}}$ & $24,0_{\mathrm{AL}}$ & $9,0_{\mathrm{AL}}$ & 31,0 & 34,8 & 65,8 & $53,0_{\mathrm{ME}}$ \\
\hline
\end{tabular}

MO - matéria orgânica; AL - alto; ME - médio; MB - muito baixo

O tratamento irrigado com cápsula foi composto por um emissor, conectado por meio de um tubo de polietileno preto (diâmetro interno $5 \mathrm{~mm}$ e parede com espessura de $2 \mathrm{~mm}$ ) a um grande frasco de Mariotte, com nível de atuação da pressão atmosférica a 0,3 m abaixo do ponto central do emissor (Figura 1). ABOUKHALED (1986) classifica de lisímetro de tensão controlada equipamentos com esse princípio de funcionamento.

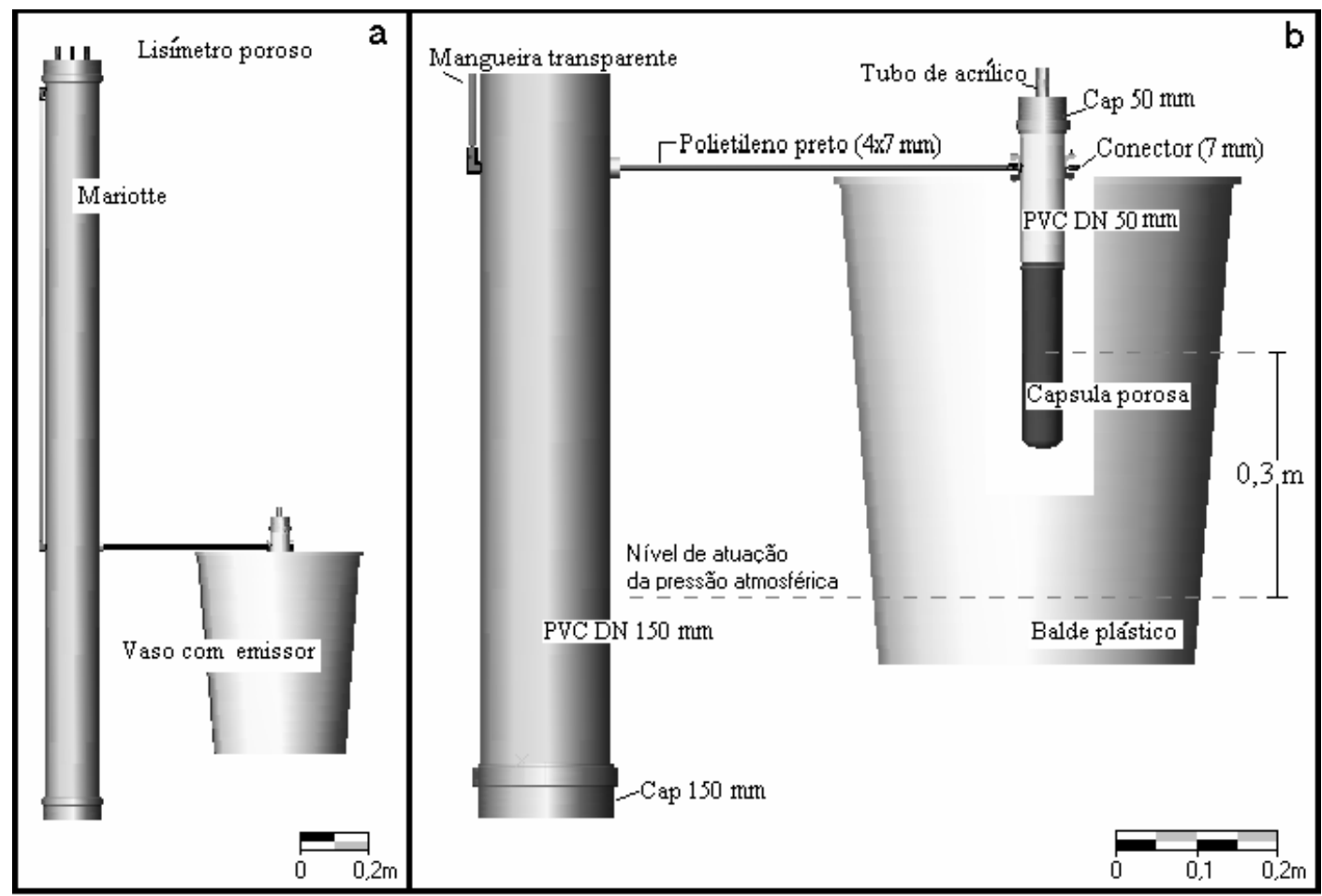

FIGURA 1. Sistema de irrigação com cápsula porosa. a) Vista geral do tubo de PVC utilizado como frasco de Mariotte. b) Detalhe dos componentes do sistema.

Neste trabalho, o equipamento era composto por duas partes: uma construída com cápsula porosa (vela de filtro), denominada de emissor, e a segunda, um tubo Mariotte que fornecia volumes conhecidos de água. O Mariotte tinha capacidade útil de $18 \mathrm{~L}$ e medidor de nível externo transparente para efetuar leitura diária do consumo.

Uma cápsula de cerâmica porosa de $220 \mathrm{~mm}$ de comprimento e $50 \mathrm{~mm}$ de diâmetro foi enterrada na posição vertical a $0,2 \mathrm{~m}$ de profundidade, medida a partir do ponto médio (em relação ao comprimento). Essa cápsula foi montada em tubo de PVC DN50 (50 mm) com cap, conectores, tubo 
de acrílico transparente e rolha de borracha. Todos esses componentes constituíram o emissor citado neste trabalho (Figura 1b), tendo sido utilizados seis recipientes com essa configuração de emissor (lisímetro de tensão). Outros seis recipientes foram irrigados manualmente por meio do monitoramento das leituras de três tensiômetros por vaso, instalados nas profundidades de 0,2; 0,4 e 0,6 m, utilizando como critério de reposição o limite de potencial mátrico de água no solo de $-30 \mathrm{kPa}$, na leitura do tensiômetro a $0,2 \mathrm{~m}$, que foi verificado diariamente com auxílio de um tensímetro eletrônico de punção.

O volume total adicionado foi estimado por meio das leituras nas três profundidades, utilizando curva de retenção estimada por meio de regressão potencial simples, com coeficiente de determinação $\mathrm{r}^{2}$ de 0,909 [(eq.(1)], sendo essa determinada em vaso por SILVA (2002), no mesmo solo estudado, para elevar a umidade até a tensão de capacidade de campo (10 kPa).

$\theta_{\mathrm{m}}=46,411 \Psi \mathrm{m}^{-0,4089}$

em que,

$\theta_{\mathrm{m}}$ - umidade com base em peso seco, $\%$, e

$\psi_{\mathrm{m}}$ - tensão da água no solo, kPa.

Nos tratamentos fertirrigados, as doses de aplicação em cobertura do nitrogênio e potássio seguiram a curva de absorção da cultura do meloeiro proposta por PINTO et al. (1996), e quanto à aplicação de fósforo, foi utilizado ácido fosfórico nas doses indicadas na Tabela 2. Os fertilizantes foram diluídos e aplicados via água de irrigação por gotejadores, nos tratamentos com tensiômetros, e por meio de cápsulas de cerâmica porosa, nos tratamentos com emissores.

TABELA 2. Distribuição de nitrogênio, fósforo e potássio ao longo do ciclo do meloeiro para os tratamentos fertirrigados.

\begin{tabular}{ccccccc}
\hline \multirow{2}{*}{ Dias Após Plantio $(D A P)$} & \multicolumn{2}{c}{ Fração de $\mathrm{N}$ Total } & \multicolumn{2}{c}{ Fração de $\mathrm{P}_{2} \mathrm{O}_{5}$ Total } & \multicolumn{2}{c}{ Fração do $\mathrm{K}_{2} \mathrm{O}$ Total } \\
\cline { 2 - 7 } & $(\%)$ & $\left(\mathrm{g} \mathrm{pl}^{-1}\right)$ & $(\%)$ & $\left(\mathrm{g} \mathrm{pl}^{-1}\right)$ & \multicolumn{1}{c}{$(\%)$} & $\left(\mathrm{g} \mathrm{pl}^{-1}\right)$ \\
\hline Plantio & - & - & - & - & 33,00 & - \\
$0-15$ & 20,00 & 4,20 & 50,00 & 12,50 & 14,20 & 3,83 \\
$15-30$ & 35,00 & 7,35 & 25,00 & 6,25 & 26,40 & 7,13 \\
$30-55$ & 45,00 & 9,45 & 25,00 & 6,25 & 26,40 & 7,13 \\
Total & - & 21,00 & - & 25,00 & - & 18,09 \\
\hline
\end{tabular}

Adaptado de PINTO et al. (1996).

As plantas foram tutoradas em haste única por meio de cordoalha de poliéster até o primeiro fio de arame (0,50 m acima da borda do vaso) do sistema de condução, do tipo espaldeira vertical, com dois fios de arame $\mathrm{n}^{-}$12. A partir desse primeiro arame, deixaram-se ramos laterais para florescimento e frutificação até o segundo arame, disposto a 1,1 m acima do primeiro. Quando a haste principal ultrapassou o segundo fio de arame, procedeu-se a poda apical. Foram deixados três frutos por planta dos ramos originados entre o $10^{\circ}$ e $18^{\circ}$ internódios. Nas brotações laterais com frutos, realizou-se a poda após a primeira folha posterior ao fruto. Para sustentação dos frutos, utilizaram-se redes plásticas penduradas nos fios de arame do sistema de condução.

Foram realizados, semanalmente, tratos fitossanitários pertinentes à cultura, até o início da maturação dos frutos, com exceção da prevenção do crestamento gomoso do caule (D. bryoniae), que foi realizado apenas aos 40 dias após o transplantio (DAT).

Avaliaram-se variáveis de crescimento da planta (área foliar, diâmetro de caule, número de folhas e alturas de plantas) e as relações solo-água-planta (porosidade livre de água no solo, efeito da água no cultivo). A área foliar foi obtida semanalmente, por meio das medidas de comprimento e 
largura de folha, conforme descrita por CARDOSO (2002), sendo o comprimento tomado do ponto de inserção do pecíolo da folha até o ápice, que apresentou relação linear de 231 amostras e coeficiente de determinação $r^{2}=0,999$. Essa metodologia baseia-se na relação entre a área do retângulo fornecido pelas medidas de comprimento e largura com a área da folha determinada por equipamento apropriado (LAI 3100, Li-Cor); assim, obteve-se um fator de correção de forma, segundo a eq.(2):

$$
\mathrm{AF}=0,9364 \mathrm{~A}
$$

em que,

$\mathrm{AF}$ - área da folha medida com LAI-3100, $\mathrm{cm}^{2}$, e

A - área do retângulo, $\mathrm{cm}^{2}$.

Para o diâmetro do caule, utilizou-se de paquímetro convencional, e para a altura de planta, trena metálica. Todas as medições de crescimento das plantas foram tomadas semanalmente. $\mathrm{O}$ consumo dos emissores porosos e as leituras de tensiômetros foram feitos diariamente, com as irrigações realizadas nos tratamentos monitorados pelos tensiômetros, em intervalos variáveis de acordo com a demanda atmosférica, normalmente a cada dois ou três dias.

Para a porosidade livre de água ( $P L A)$, primeiro determinou-se a percentagem de poros do solo $(P)$ por meio da eq.(3) e, em seguida, subtraiu-se dessa porosidade o volume de água presente no solo, fornecido pelas leituras dos tensiômetros, conforme a eq.(4).

$$
\mathrm{P}=\left(1-\frac{\mathrm{ds}}{\mathrm{dp}}\right) 100
$$

em que,

$\mathrm{P}$ - porosidade do solo, $\%$;

ds - densidade do solo, $\mathrm{Mg} \mathrm{m}^{-3}$, e

$\mathrm{dp}$ - densidade das partículas, $\mathrm{Mg} \mathrm{m}^{-3}$.

$$
\mathrm{PLA}=\mathrm{P}-\left(\theta_{\mathrm{m}} \mathrm{ds}\right)
$$

em que,

PLA - porosidade livre de água, \%;

$\mathrm{P}$ - porosidade do solo, \%;

$\theta \mathrm{m}$ - umidade com base em peso seco, $\%$, e

ds - densidade do solo, $\mathrm{Mg} \mathrm{m}^{-3}$.

Para as variáveis de desenvolvimento (altura, número de folhas, diâmetro do caule e área foliar), foram realizadas análises de variância para cada período de amostragem $(D A T)$, tomando como fatores os sistemas e os níveis de adubação $(2 \times 2)$, delineados em blocos inteiramente ao acaso, com três repetições. As variáveis de produção (massa de frutos e massa da parte aérea) foram analisadas como experimentos fatoriais, em delineamento de blocos inteiramente ao acaso.

\section{RESULTADOS E DISCUSSÃO}

A análise multivariada permitiu avaliar o efeito das interações do tempo com o sistema e níveis de adubações, no período de crescimento vegetativo do meloeiro (Tabela 3). Para as variáveis altura de planta e área foliar, desde o $18^{\circ}$ até o $38^{\circ} D A P$, verifica-se, pelo nível de significância $(\mathrm{P}<0,10 ; 0,05$ e $0,01)$, que houve diferenciação entre os níveis de cada fator estudado com o tempo. Os valores $\mathrm{F}$ para as variáveis número de folhas e diâmetro do caule não foram mostrados na Tabela 3, por não apresentarem interações significativas $(p>0,10)$. 
MORRISON (1990) e LIMA (1996) recomendam a utilização de análise estatística univariada para os casos de ocorrerem interações significativas. Esse procedimento tem como objetivo verificar o efeito de cada um dos fatores estudados para cada época de coleta de dados, sendo, nesse caso, apresentado na Tabela 4.

TABELA 3. Análise multivariável da altura de plantas e área foliar de meloeiro rendilhado.

\begin{tabular}{|c|c|c|c|c|c|c|}
\hline \multirow{4}{*}{ Interações } & \multicolumn{6}{|c|}{ Estatísticas } \\
\hline & \multicolumn{3}{|c|}{ Altura da Planta } & \multicolumn{3}{|c|}{ Área Foliar } \\
\hline & Wilks & Pillai's & Hotelling- & Wilks & Pillai’s & Hotelling- \\
\hline & Lambda & Trace & Lawley $\mathrm{Tr}$ & Lambda & Trace & Lawley Tr. \\
\hline & \multicolumn{6}{|c|}{ Valores F } \\
\hline Tempo x Sistema & $4,21^{\oplus}$ & $4,21^{\oplus}$ & $4,21^{\oplus}$ & $4,6^{\oplus}$ & $4,6^{\oplus}$ & $4,6^{\oplus}$ \\
\hline Tempo x Adubação & $8,03 *$ & $8,03 *$ & $8,03 *$ & $11,11 *$ & $11,11 *$ & $11,11 *$ \\
\hline Tempo x Sistema x Adubação & $4,08^{\oplus}$ & $4,08^{\oplus}$ & $4,08^{\oplus}$ & $30,13 * *$ & $30,13 * *$ & $30,13 * *$ \\
\hline
\end{tabular}

$* *, * \mathrm{e}^{\oplus}$ significativos a $1 ; 5$ e $10 \%$, respectivamente.

TABELA 4. Variáveis de crescimento do meloeiro aos 18; 24; 31 e 38 dias após o plantio (DAP).

\begin{tabular}{ccccccccc}
\hline & \multicolumn{7}{c}{ Dias Após o Plantio $(D A P)$} \\
\cline { 2 - 9 } Tratamentos & \multicolumn{7}{c}{ Altura da Planta $(\mathrm{m})$} \\
\cline { 2 - 8 } & 18 & 24 & 31 & 38 & 18 & 24 & 31 & 38 \\
\hline EF & $26,17 \mathrm{a}$ & $52,23 \mathrm{a}$ & $91,67 \mathrm{a}$ & $130,66 \mathrm{ab}$ & $0,09 \mathrm{a}$ & $0,16 \mathrm{a}$ & $0,31 \mathrm{a}$ & $0,46 \mathrm{~b}$ \\
ESF & $22,00 \mathrm{a}$ & $41,80 \mathrm{a}$ & $65,67 \mathrm{a}$ & $84,66 \mathrm{~b}$ & $0,07 \mathrm{a}$ & $0,10 \mathrm{a}$ & $0,14 \mathrm{~b}$ & $0,21 \mathrm{~b}$ \\
TF & $17,50 \mathrm{a}$ & $40,33 \mathrm{a}$ & $87,00 \mathrm{a}$ & $141,0 \mathrm{a}$ & $0,06 \mathrm{a}$ & $0,12 \mathrm{a}$ & $0,30 \mathrm{a}$ & $0,65 \mathrm{a}$ \\
TSF & $23,33 \mathrm{a}$ & $51,40 \mathrm{a}$ & $101,00 \mathrm{a}$ & $105,5 \mathrm{ab}$ & $0,08 \mathrm{a}$ & $0,15 \mathrm{a}$ & $0,29 \mathrm{a}$ & $0,40 \mathrm{~b}$ \\
\hline
\end{tabular}

Médias seguidas por letras distintas na mesma coluna diferem entre si, a 5\% de significância.

EF - emissor com fertirrigação; ESF - emissor sem fertirrigação, TF - tensiômetro com fertirrigação e TSF - tensiômetro sem fertirrigação. *Valores médios de três plantas.

Os sistemas de reposição de água, com ou sem fertirrigação, não evidenciaram diferenças entre tratamentos até aos $31 \mathrm{DAP}$. Aos $31 \mathrm{DAP}$, a variável área foliar das plantas, para o tratamento monitorado por emissor sem fertirrigação, foi inferior à obtida nos outros tratamentos $(\mathrm{P}<0,05)$. Apenas no quarto período de amostragem (38 DAP), a área foliar foi superior aos demais tratamentos.

Para o terceiro período de amostragem $(31 \mathrm{DAP})$, os tratamentos com tensiômetro sem fertirrigação $(T S F)$, tensiômetros com fertirrigação $(T F)$ e emissor com fertirrigação ( $E F$ ) não diferiram entre si. A variável de desenvolvimento (área foliar) evidenciou melhor o efeito dos tratamentos nos dois últimos períodos de amostragem. Ela conferiu maior desenvolvimento para o $T F$ e o menor para o emissor na ausência de fertirrigação $(E S F)$. Ainda, em relação à área foliar, os outros dois tratamentos ( $E F$ e $T S F)$ foram semelhantes entre si, pelo teste de Tukey, a 5\% de probabilidade. A partir dos $40 D A T$, uma das plantas irrigadas do tratamento $E F$ apresentou sintomas de crestamento gomoso do caule (D. bryoniae), seguido de morte. Passada mais uma semana, o mesmo sintoma foi verificado nas outras duas parcelas do mesmo tratamento $(E F)$, e atribuiu-se como causa a elevada umidade na superfície do solo aliada à fertilidade, que deixou as células do tecido vegetal mais tenras e, conseqüentemente, suscetíveis à entrada de patógenos. Partindo deste acontecimento, resolveu-se avaliar a porosidade livre de água (PLA) e pôde-se constatar que os tratamentos irrigados pelo emissor poroso proporcionavam PLA média de $15 \%$ e até mesmo inferior a $10 \%$ em alguns dias. Esses valores de PLA estão abaixo do mínimo (10 - 20\%) indicado por REICHARDT (1990). Para os tratamentos irrigados com base na leitura dos tensiômetros, a PLA permaneceu, em média, com 35\%, favorecendo boa relação ar-água durante todo o experimento. 
Nas Figuras 2 e 3, apresenta-se a variação da PLA para os emissores e tensiômetros no período inicial de avaliação.

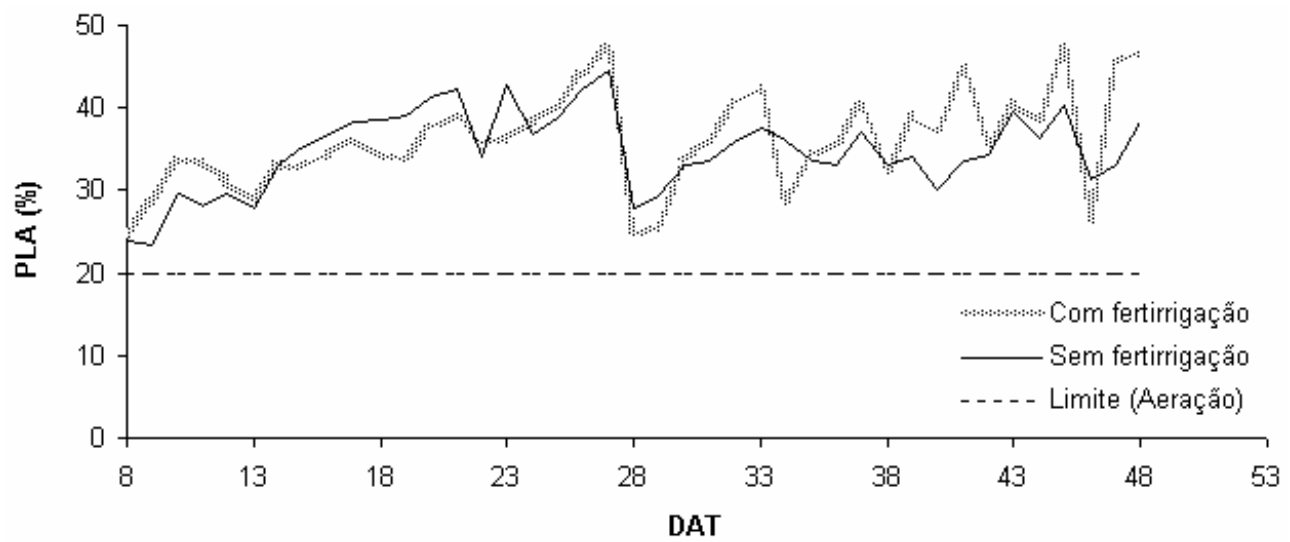

FIGURA 2. Porosidade livre de água, média dos tratamentos irrigados via tensiômetros, com e sem fertirrigação.

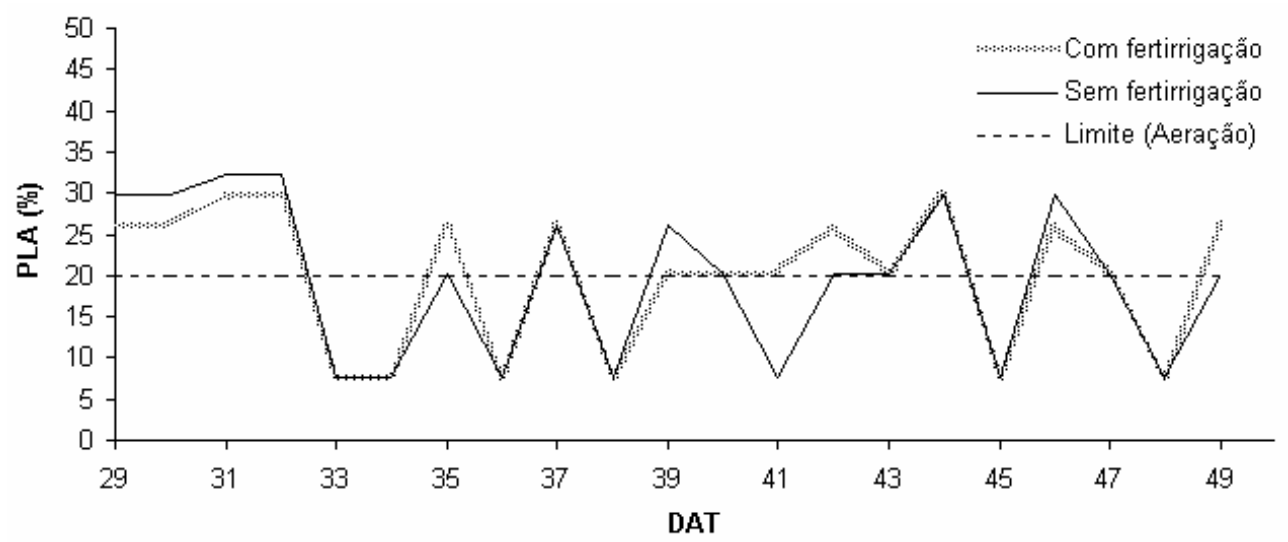

FIGURA 3. Porosidade livre de água, média dos tratamentos irrigados via emissores, com e sem fertirrigação.

Outra verificação quanto à $P L A$ foi testada em laboratório, por meio de estimativa da variação da PLA ao longo do comprimento do emissor em posição vertical, sendo submetido a diferentes alturas de carga hidráulica $(30 ; 40 ; 50$ e $60 \mathrm{~cm})$ e medida a respectiva tensão com auxílio do tensímetro. Sendo o teste realizado com o emissor em posição vertical e altura da coluna de água pendente, tendo o centro do emissor como referência, estimou-se a PLA ao longo do emissor (a cada $1 \mathrm{~cm}$ ) por meio das eqs.(1), (3) e (4) e obteve-se o conjunto de pontos visualizados na Figura 4.

Os dados apresentados na Figura 4 mostram que, para carga hidráulica de $30 \mathrm{~cm}$, quase toda a superfície da cápsula do emissor encontra-se com PLA inferior a 20\%. Na carga de 0,4 m, praticamente metade da cápsula estaria em condições favoráveis. Porém, para toda superfície da cápsula permanecer com PLA acima de $20 \%$, foi necessário estabelecer cargas hidráulicas a partir de 0,5 m. Vale salientar que esse tipo de cápsula permite tensões de até aproximadamente $20 \mathrm{kPa}$, além do mais, à medida que o ponto avaliado no solo se distancia da superfície do emissor, mais negativo é esse valor, sendo necessária a utilização de maior quantidade de energia para que a planta absorva água nesse nível. 


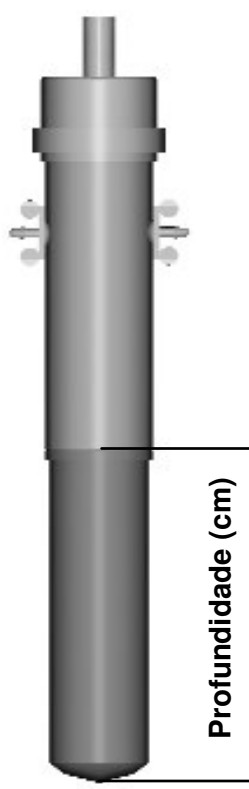

\section{Carga hidráulica}

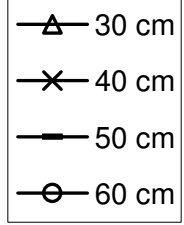

Observação: Para a determinação das cargas

hidráulicas, a profundidade de referência utilizada foi o ponto médio das cápsulas porosas.

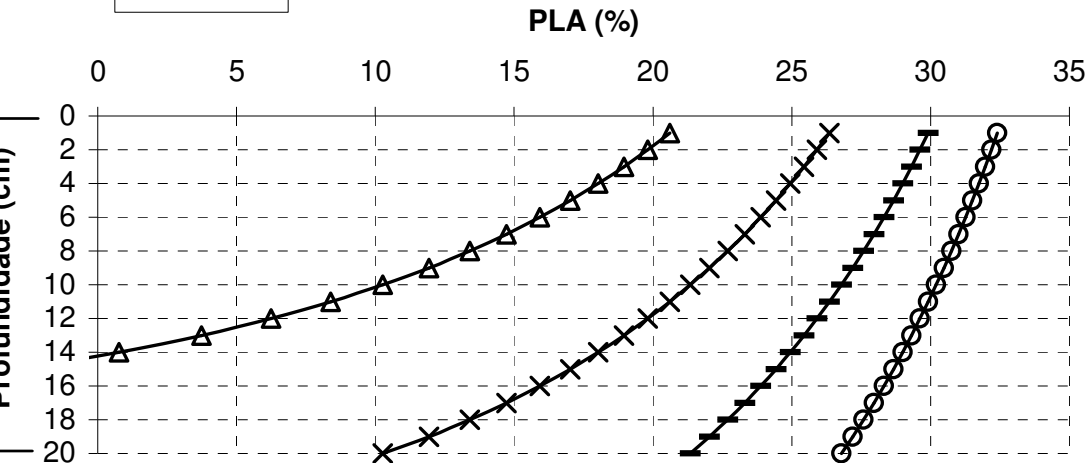

FIGURA 4. Estimativa da variação da porosidade livre de água $(P L A)$ no solo para diferentes níveis de cargas hidráulicas do emissor poroso.

Com relação à variação do potencial matricial (média das três profundidades tanto para os tensiômetros como para os emissores porosos), pode-se observar que as tensões apresentaram maiores desvios para os tensiômetros e menores no caso dos emissores, 9,10\% e 1,33\%, respectivamente (Figuras 5 e 6). Apesar de os emissores terem sido mantidos com pouca variação no potencial do solo, nesses, o nível de tensão foi baixo, o que contribuiu para retardar o desenvolvimento vegetativo das plantas sem fertirrigação, bem como favorecer problemas fitossanitários, causando a perda dos tratamentos citados anteriormente. Teoricamente, a utilização do emissor deveria promover tensões constantes, mas, devido à histerese, aos tempos de resposta e de equilíbrio, à redistribuição de água no solo, às variações ao longo do dia da absorção de água e do sistema não-isotérmico, houve essa variação.

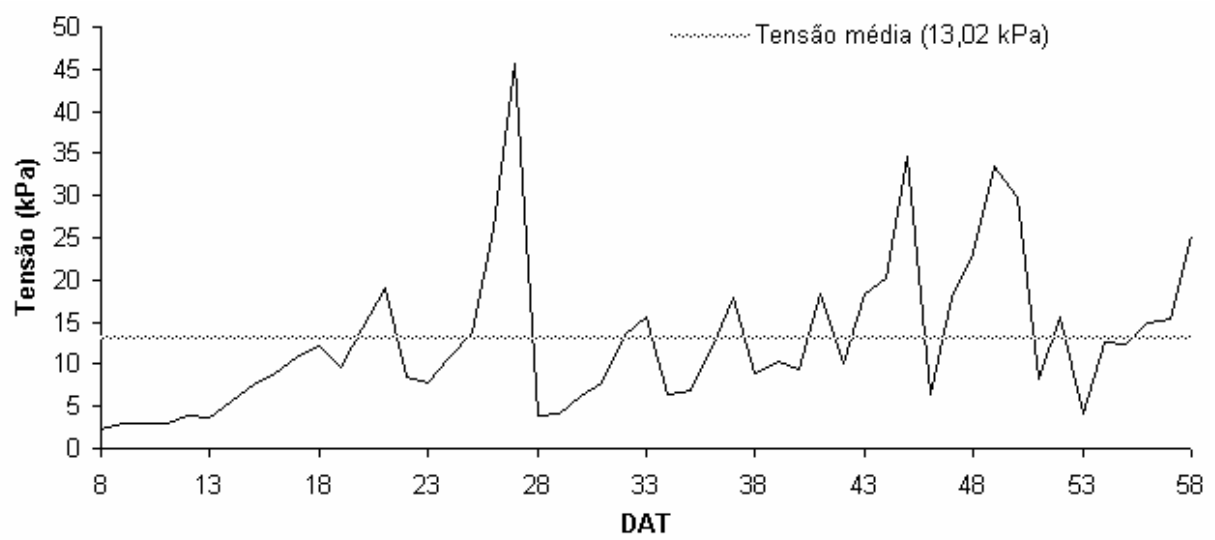

FIGURA 5. Potencial mátrico médio para os tratamentos irrigados via tensiômetros. 


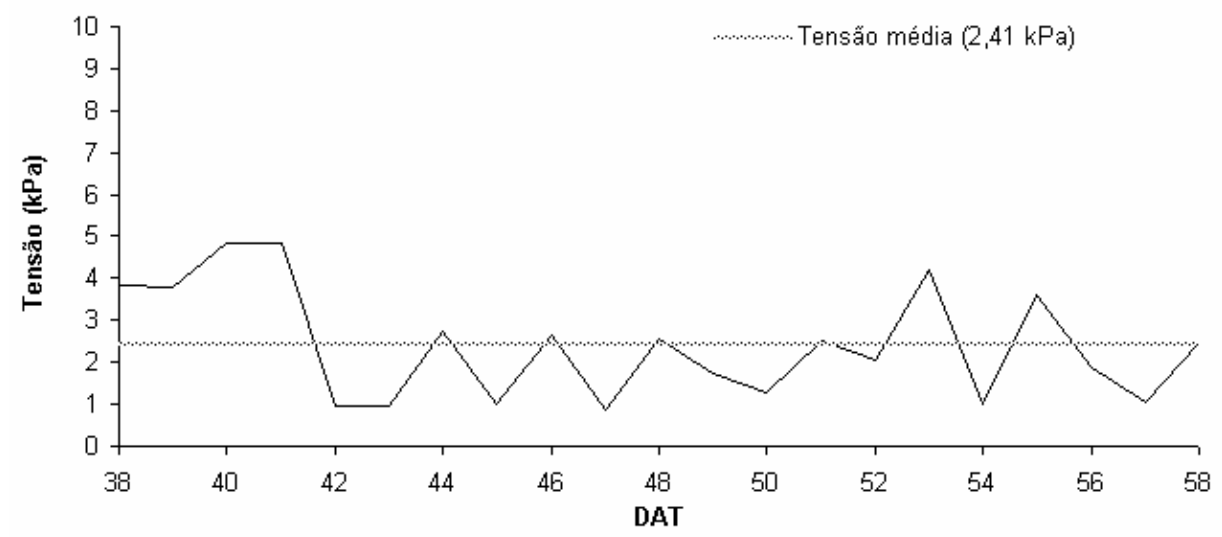

FIGURA 6. Potencial mátrico médio para os tratamentos irrigados via emissor poroso.

Por meio da análise estatística, foi possível avaliar os dados de produção e biomassa seca ao final do ciclo (Tabela 4).

Para todos os tratamentos, exceto o $E S F$, a massa média dos frutos foi superior a $550 \mathrm{~g}$. FILGUEIRAS et al. (2000) consideram esse valor (550 g) a massa mínima de padrão comercial. O $T S F$ foi o tratamento que atingiu peso intermediário, não diferindo dos outros dois. Apenas o tratamento com tensiômetro mais fertilizantes $(T F)$ foi superior ao ESF para essa variável. Por fim, a massa seca de folhas mais caule confirma as diferenças apresentadas anteriormente entre os tratamentos $T F$ e $E S F$, com 102,88 e 41,49 g, respectivamente.

TABELA 4. Produção dos tratamentos com tensiômetros e emissores com e sem fertilizantes.

\begin{tabular}{ccc}
\hline Tratamento & Massa do Fruto $(\mathrm{g})$ & Folhas + Caule $(\mathrm{g})^{*}$ \\
\hline TF & $2.493,80 \mathrm{a}$ & $102,88 \mathrm{a}$ \\
TSF & $1.070,40 \mathrm{ab}$ & $52,18 \mathrm{~b}$ \\
ESF & $512,70 \mathrm{~b}$ & $41,49 \mathrm{~b}$ \\
\hline Média & $1.458,73$ & 70,58 \\
C.V.(\%) & 39,06 & 22,79 \\
D.M.S. & $1.525,20$ & 40,61 \\
\hline
\end{tabular}

Médias seguidas por letras distintas na mesma coluna diferem entre si, a 5\% de significância.

* Massa após secagem em estufa por $72 \mathrm{~h}$ a $70{ }^{\circ} \mathrm{C}$, com circulação forçada. TF - tensiômetro, com adição de fertilizante; TSF - tensiômetro, sem adição de fertilizante; ESF - Emissor, sem adição de fertilizante.

\section{CONCLUSÕES}

A irrigação monitorada com tensiômentros manteve o solo em condição ideal de porosidade livre de água, ou seja, acima do valor limite de aeração.

No lisímetro de tensão, o emissor poroso manteve pequenas variações de potencial de água no solo, porém, com a carga hidráulica aplicada de $-30 \mathrm{kPa}$, teve-se excesso de umidade para o solo avaliado.

A proporção entre o volume de água e de ar no solo é fator vital que deve ser reconhecido, principalmente em cultivos sensíveis à saturação.

O meloeiro apresentou baixo rendimento em condição inferior a $20 \%$ de porosidade livre de água. 


\section{REFERENCIAS}

ABOUKHALED, A.; ALFARO, A.; SMITH, M. Lysimeters. Roma: FAO, 1986. 68 p. (Irrigation and Drainage Paper, 39).

BATAGLIA, O.C. Sistemas de irrigação em vasos para experimentos de adubação. Revista Brasileira de Ciência do Solo, Campinas, v.13, p.81-6, março 1989.

BRANDÃO FILHO, J.U.T.; VASCONCELOS, M.A.S. A cultura do meloeiro. In: GOTO, R.; TIVELLI, S.W. Produção de hortaliças em ambiente protegido: condições subtropicais. São Paulo: Fundação Editora da UNESP, 1998. p.161-94.

CARDOSO, S.S. Doses de $\mathrm{CO}_{2}$ e de potássio através da irrigação no meloeiro rendilhado (Cucumis melo L.) cultivado em ambiente protegido. 2002. 101 f. Tese (Doutorado em Irrigação e Drenagem) Escola Superior de Agricultura "Luiz de Queiroz", Universidade de São Paulo, Piracicaba, 2002.

EMPRESA BRASILEIRA DE PESQUISA AGROPECUÁRIA. Centro Nacional de Pesquisa de Solos. Sistema brasileiro de classificação de solos. Rio de Janeiro, 1999. 412 p.

FILGUEIRAS, H.A.; MENEZES, J.B.; ALVES, R.E. (Coord.). Melão: pós-colheita. Brasília: EMBRAPA Comunicação para Transferência de Tecnologia, 2000. 43 p.

GUALBERTO, R.; RESENDE, F.V.; LOSAOS, P.H.L. Produtividade e qualidade do melão rendilhado em ambiente protegido, em função do espaçamento e sistema de condução. Horticultura Brasileira, Brasília, v.19, n.3, p.240-3, nov. 2001.

LIMA, C.G. Análise de dados longitudinais provenientes de experimentos em blocos casualisados. 1996. 126 f. Tese (Doutorado em Estatística Experimental) - Escola Superior de Agricultura "Luiz de Queiroz", Universidade de São Paulo, Piracicaba, 1996.

MORRISON, D.F. Multivariate statistical methods. $3^{\text {th }}$. New York: McGraw-Hill, 1990. $414 \mathrm{p}$.

PINTO, J.M.; SOARES, J.M.; PEREIRA J.R.; COSTA, N.D.; BRITO, L.T.L.; FARIA, C.M.B.; MACIEL, J.L. Sistemas de cultivo de melão com aplicação de fertilizantes via água de irrigação. Petrolina: EMBRAPA-CPATSA, 1996. 24 p. (Boletim de Pesquisa, 45).

REICHARDT, K. A água em sistemas agrícolas.São Paulo: Manole, 1990. 188 p.

RIZZO, A.A.N. Avaliação de caracteres agronômicos e qualitativos de cinco cultivares de melão rendilhado (Cucumis melo var. reticulatus Naud.) e da heterose em seus híbridos F1. 1999. $59 \mathrm{f}$. Dissertação (Mestrado em Produção Vegetal) - Faculdade de Ciências Agrárias e Veterinárias, Universidade Estadual Paulista, Jaboticabal, 1999.

RIZZO, A.A.N.; BRAZ, L.T. Características de cultivares de melão rendilhado cultivadas em casa de vegetação. Horticultura Brasileira, Brasília, v.19, n.3, p.237-40, nov. 2001.

SILVA, E.F.F. Manejo da fertirrigação e controle da salinidade na cultura do pimentão utilizando extratores de solução do solo. 2002. 136 f. Tese (Doutorado em Irrigação e Drenagem) - Escola Superior de Agricultura "Luiz de Queiroz", Universidade de São Paulo, Piracicaba, 2002.

SILVA, T.J.A.; MACHADO, C.C.; BONFIM-SILVA, E.D.; COELHO, R.D. Coeficiente de cultivo $(\mathrm{Kc})$ do meloeiro tipo rendilhado cultivado em ambiente protegido. Irriga, Botucatu, v.9, n.1, p.72-9, 2004. 